\title{
AIDS-related opportunistic mycoses seen in a tertiary care hospital in North India
}

\author{
Correspondence \\ Anupriya Wadhwa \\ dranupriyawadhwa@gmail.com
}

Received 15 August 2006

Accepted 1 May 2007

\section{Anupriya Wadhwa, ${ }^{1}$ Ravinder Kaur, ${ }^{1}$ Satish Kumar Agarwal, ${ }^{2}$ Shyama Jain ${ }^{3}$ and Preena Bhalla ${ }^{1}$}

\author{
${ }^{1}$ Department of Microbiology, Maulana Azad Medical College, New Delhi, India \\ ${ }^{2}$ Department of Medicine, Maulana Azad Medical College, New Delhi, India \\ ${ }^{3}$ Department of Pathology, Maulana Azad Medical College, New Delhi, India
}

\begin{abstract}
Sixty symptomatic confirmed human immunodeficiency virus (HIV)-positive adult patients, of both sexes, suspected of having a fungal infection were taken as a study population, and the clinicomycological profile was correlated with the immunological status of the patients with particular reference to CD4 counts. Relevant samples were collected and subjected to direct microscopy, fungal culture and serology. CD4 counts were determined by flow cytometry. Patients belonged to the age group of 17-65 years, with a male : female ratio of $4.8: 1$. Heterosexuality was the commonest mode of transmission. Candidiasis was the most common diagnosis $(41.7 \%)$, followed by cryptococcosis $(10.0 \%)$, and pneumocystinosis and aspergillosis (8.3\% each). Two cases of histoplasmosis were also diagnosed. A low mean CD4 count of $<200$ cells $\mu l^{-1}$ was seen with most fungal infections. A total of $73 \%$ of patients belonged to World Health Organization (WHO) stage 4 , while $23.33 \%$ belonged to stage 3 . Thirty one patients $(51.67 \%)$ belonged to Centers for Disease Control and Prevention (CDC) stage C3. Various fungal infections correlated well with the mean CD4 counts. It was difficult to correlate statistically WHO and CDC staging because of the small sample size. However, it was possible to assess to a limited extent the possibility of using clinical diagnosis to predict the status of progression of HIV infection in a resource-poor outpatient setting.
\end{abstract}

\section{INTRODUCTION}

AIDS caused by the human immunodeficiency virus (HIV) is the most important public health problem of modern times (Rosen, 1994). As per the global estimate of the World Health Organization (WHO) and Joint United Nations Programme on HIV/AIDS (UNAIDS) in December 2005, the total number of patients with HIV in 2005 was 40.3 million, with 4.9 million newly infected people and 3.1 million AIDS-related deaths (UNAIDS/WHO, 2005). HIV made a delayed entry into India, but its spread has been very rapid and at present is in an advanced stage of the epidemic in some states of the country (NACO, 1999).

Though HIV is the causative agent of AIDS, most morbidity and mortality in AIDS patients results from opportunistic infections; approximately $80 \%$ of these patients are seen to die as a result of such an infection rather than from HIV. Mostly the infections seen in AIDS patients are endemic to the geographical region, and

Abbreviations: ART, anti-retroviral treatment; CDC, Centers for Disease Control and Prevention; HIV, human immunodeficiency virus; PCP, pneumocystis pneumonia; UNAIDS, Joint United Nations Programme on HIV/AIDS; WHO, World Health Organization. involve many organs and organ systems simultaneously with a tendency to disseminate (George et al., 1996; Sivaraman et al., 1992).

There are major differences in the spectrum of opportunistic infections in India and in the West (White \& Zaman, 1992; Aquinas et al., 1996). Limited studies from India have shown that tuberculosis is the most common opportunistic infection, followed by a host of other bacterial, parasitic, viral and fungal infections. Various mycoses form the bulk of opportunistic infections in AIDS patients and are increasing in the form of an epidemic parallel to the AIDS epidemic (Mirdha et al., 1993). The data from India on the spectrum of fungal infections in HIV/AIDS patients, and the clinical and immunological profile of these patients are scarce. Hence our aim was to study the regional profile of fungal opportunistic infections and their correlation with the immunological profile of the patients.

\section{METHODS}

Study population and design. Sixty symptomatic confirmed adult HIV-positive patients, of both sexes, suspected of having a fungal 
infection were taken as subjects. Cases were recruited from the outpatient department, wards and the Anti-Retroviral Treatment Clinic of Lok Nayak Hospital and GB Pant Hospital, New Delhi. All patients were evaluated by a pre-designed protocol covering the biodata, history, including high-risk behaviour, mode of transmission, marital status, partner status, presenting complaints and physical examination.

Microscopy, culture and identification. Depending on the clinical symptoms, relevant clinical samples were collected with complete universal precautions and relevant methods were used for diagnosis and isolation, which included a battery of tests as per standard procedures (Forbes et al., 2002; Milne, 1996). The samples were subjected to direct microscopy using Gram and Giemsa staining, $\mathrm{KOH}$ mounts, India ink preparations, Gomori methenamine silver staining and toluidine blue $\mathrm{O}$ staining depending on the type of specimen and the suspected infection in the patient.

Fungal culture was done on Sabouraud dextrose agar, with and without chloramphenicol $\left(16 \mu \mathrm{g} \mathrm{ml}^{-1}\right)$, brain heart infusion agar and $5 \%$ sheep blood agar. Specimens were streaked in duplicate; one set of inoculated slants was incubated at $25{ }^{\circ} \mathrm{C}$ and the other at $37{ }^{\circ} \mathrm{C}$, and they were examined every other day for growth up to 4-6 weeks before discarding as negative. Samples inoculated on blood agar were incubated for 24-48 h and samples on brain heart infusion agar were incubated for 1-2 weeks (Forbes et al., 2002; Koneman et al., 1997). Fungal growth was identified by colony morphology, Gram staining, lactophenol cotton blue preparation and Riddle's slide culture as per standard recommended procedures (Moore \& Jaciow, 1979).

Identification \& speciation of yeast isolates was done on the basis of germ tube production, morphology on corn meal agar with Tween 80 (Hi Media), HiCrome candida agar (Hi Media), carbohydrate fermentation tests and assimilation tests using yeast nitrogen base agar (Hi Media) as per standard recommended procedures (Forbes et al., 2002; Koneman et al., 1997; Moore \& Jaciow, 1979).

Serology and assessment of immune status. Serology was performed on the serum/cerebrospinal fluid samples collected from the patients using antigen detection by latex agglutination for Cryptococcus, using the cryptococcal antigen latex agglutination system (CALAS) (Meridian Bioscience), and the Aspergillus sp. using Pastrorex aspergillus (Sanofi Diagnostics Pasteur), direct immunofluorescence for detection of Pneumocystis jiroveci in sputum/ bronchioalveolar lavage samples using MERIFLUOR-pneumocystis kit (Meridian Bioscience) and antibody detection by immunodiffusion for Histoplasma sp. and Blastomyces sp. using the ID-fungal antibody kit (4AG - Aspergillus, Blastomyces, Coccidioides, Histoplasma) from IMMY Immuno Mycologics as per the manufacturers' instructions. CD4 count was determined for each patient enrolled in our study by flow cytometry using the fluorescent activated cell sorter BD FACS Count system (Becton Dickinson) as per the manufacturer's instructions.

\section{RESULTS AND DISCUSSION}

During the 15 month study from February 2005 to April 2006, 60 patients with known HIV positive status and suspected fungal infections were enrolled to determine the spectrum of fungal infections and their correlation with CD4 counts.

Patients had a mean age of $34 \pm 9$ years with $82 \%$ patients in the age group of $21-40$ years, the most productive age group of the country. The male: female ratio in our study was $4.8: 1$. Two of our patients were intersexes (Table 1).
Table 1. Demographic profile of study population

\begin{tabular}{|lcc|}
\hline $\begin{array}{l}\text { Demographic } \\
\text { profile }\end{array}$ & No. of males (\%) & No. of females (\%) \\
\hline Age group & & \\
\hline $15-20$ & $0(0)$ & $1(10)$ \\
$21-25$ & $4(8.3)$ & $1(10)$ \\
$26-30$ & $16(33.3)$ & $4(40)$ \\
$31-35$ & $11(22.9)$ & $2(20)$ \\
$36-40$ & $8(16.6)$ & $1(10)$ \\
$41-45$ & $4(8.3)$ & $1(10)$ \\
$46-50$ & $1(2.1)$ & $0(0)$ \\
$51-55$ & $2(4.2)$ & $0(0)$ \\
$56-60$ & $1(2.1)$ & $0(0)$ \\
$61-65$ & $1(2.1)$ & $0(0)$ \\
Marital status & $39(81.2)$ & $9(90)$ \\
Married & $9(18.8)$ & $1(10)$ \\
Unmarried & & $9(90)$ \\
Partner status & $13(33.3)$ & $0(0)$ \\
Positive & $8(20.5)$ & $0(0)$ \\
Negative & $18(46.2)$ & \\
Not known & & \\
\end{tabular}

Our findings are consistent with the data given by the National AIDS Control Organization (NACO) and in studies elsewhere in India (Kothari \& Goyal, 2001; Kumarasamy et al., 1995). While the males belonged to a wider age spectrum, the females were a considerably younger population, and most of them acquired infection from their spouses, reflecting the male dominance in Indian society and emphasizing an increased need for awareness and counselling of both the spouses. The sexual mode of transmission was the commonest, seen in 32 $(53.3 \%)$ patients (heterosexuality accounting for $94 \%$ of these), as seen in other studies in India (Kothari \& Goyal, 2001; Kumarasamy et al., 1995; Kaur et al., 1992), followed by intravenous drug abuse and blood transfusion in 5 and 3 patients (8.3 and $5 \%$ ), respectively, while mode of transmission was not known in $18(30 \%)$ patients.

The common presenting complaints were weight loss $(88.3 \%)$, loss of appetite $(75 \%)$ and fever $(71.7 \%)$, similar to other studies from India (Kothari \& Goyal, 2001; Kaur et al., 1992) (Fig. 1). A history of tuberculosis (60\%) was the most common past history elicited, as reported in other studies from India (Kothari \& Goyal, 2001; Kumarasamy et al., 1995; Vajpayee et al., 2003).

Lymphopenia and anaemia were noted in 23.3 and $65 \%$ of patients, respectively, followed by leucopenia in $11.6 \%$ of patients, as also seen in a study in Vellore (Kaur et al., 1992), while two patients had pancytopenia with haemoglobin levels of $3.8 \mathrm{~g} \mathrm{dl}^{-1}$ and $6.5 \mathrm{~g} \mathrm{dl}^{-1}$. Neutropenia was seen in $5(8.3 \%)$ patients.

From 60 patients, 140 samples were collected and processed (Table 2). The gastrointestinal system was 


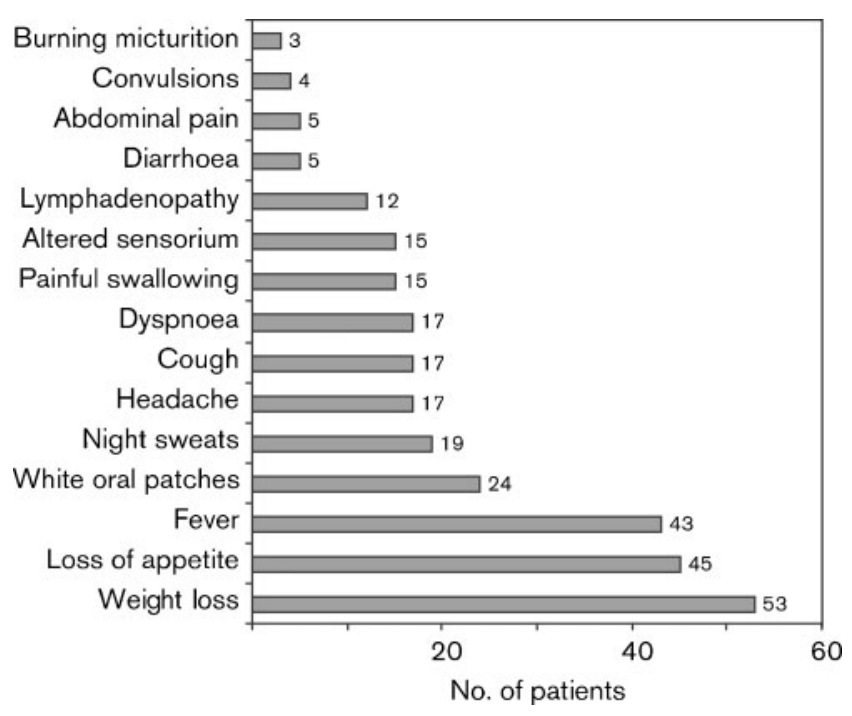

Fig. 1. Signs and symptoms at presentation.

involved in $33(55 \%)$ patients, the respiratory system in 21 ( $35 \%)$, followed by the central nervous system in $17(28.3 \%)$ and genitourinary involvement in $2(3.3 \%)$ patients. Four patients $(6.7 \%)$ showed skin involvement (two with scabies, one with pyoderma and one with anti-retroviral treatment (ART)-associated hyperpigmentation). Thirteen patients $(16.7 \%)$ showed multi-system involvement.

Oral candidiasis was the most common form of candi-

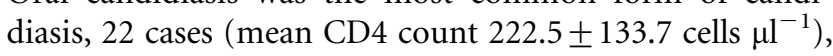
3 among the 22 patients also had oesophageal candidiasis (mean CD 4 count $85 \pm 78$ cells $\mu \mathrm{l}^{-1}$ ), 1 out of 22 also had Candida diarrhoea and 1 out of 22 also had candiduria. Three cases were diagnosed as Candida pneumonia (mean CD4 count $161 \pm 73.08$ cells $\mu \mathrm{l}^{-1}$ ) (Table 3 ). A CD4 count of $<200$ cells $\mu l^{-1}$ and a viral load of $>10000$ copies $\mathrm{ml}^{-1}$, along with factors like tobacco consumption, poor oral hygiene and xerostomia, have been shown to facilitate the occurrence of oral lesions in these individuals (Bravo et al.,
2006). This may also play a role in patients in our study due to the abundance of such associated factors in them. Also the severity of lesions has been shown to increase with a fall in CD4 counts in a study from India (Lattif et al., 2004). At a CD4 count of $<50$ cells $\mu \mathrm{l}^{-1}$, oesophageal thrush becomes common. Two of our patients with oesophagitis had CD4 counts $<50$ cells $\mu \mathrm{l}^{-1}$, which is in agreement with most studies (Maenza et al., 1996). Candida albicans $(59.3 \%)$ was the commonest Candida spp. isolated, followed by Candida glabrata $(14.8 \%)$ and Candida parapsilosis (11.8\%), while Candida guilliermondii, Candida krusei, Candida lipolytica and Candida tropicalis were isolated from one patient each. Non-albicans Candida species were isolated only from oral thrush. Studies from the USA have reported C. tropicalis and Candida dubliniensis as the common non-albicans Candida spp. in thrush, but none of our isolates was C. dubliniensis (Bravo et al., 2006; Martinez et al., 2002). All three patients with oesophageal candidiasis had infection with C. albicans, the most common Candida spp. reported in invasive candidiasis (de Repentigny et al., 2004; Phillips et al., 1996).

Six patients had cryptococcosis. One patient presented with both pulmonary and central nervous system cryptococcosis, while cryptococcal meningitis and pulmonary cryptococcosis alone were seen in four patients and one patient, respectively. The CD4 counts of five of these patients were $\leqslant 200$ cells $\mu \mathrm{l}^{-1}$, and three among these five had a CD4 count $<100$ cells $_{\mu l}^{-1}$ (mean CD4 count $138.8 \pm 92.11$ cells $\mu \mathrm{l}^{-1}$ in cryptococcal meningitis) (Table 3 ). The incidence of cryptococcal meningitis was seen to be $8.3 \%$, similar to the data from the USA, where it was estimated to be 6.1$8.5 \%$ (Currie \& Casadevall, 1994).

Five patients $(8.3 \%)$ had pneumocystis pneumonia (PCP) in our study. Three patients had CD4 counts $<200$ cells $\mu \mathrm{l}^{-1}$ and one patient had a count as low as 94 cells $\mu \mathrm{l}^{-1}$ (Table 3). Incidence of PCP in AIDS patients in developing countries, including India, has been low (Udwadia et al., 2005; Nissapatorn et al., 2003). This may be due to lack of diagnosis or prevalence of more virulent conditions, like tuberculosis, leading to pulmonary disease before PCP

Table 2. Correlation between fungi isolated/detected and clinical specimens

\begin{tabular}{|c|c|c|c|c|c|c|c|c|}
\hline Fungus & Total & Oral swab & Sputum & CSF & Urine & Stool & FNAC /Bx & Blood \\
\hline Candida spp. & 27 & 22 & 3 & 0 & 1 & 1 & 0 & 0 \\
\hline C. albicans & 16 & 11 & 3 & 0 & 1 & 1 & 0 & 0 \\
\hline$P$. jiroveci & 5 & 0 & 5 & 0 & 0 & 0 & 0 & 0 \\
\hline Cryptococcus neoformans & 7 & 0 & 2 & 5 & 0 & 0 & 0 & 0 \\
\hline S. cerevisiae & 2 & 1 & 0 & 0 & 0 & 1 & 0 & 0 \\
\hline R. rubra & 1 & 1 & 0 & 0 & 0 & 0 & 0 & 0 \\
\hline Histoplasma capsulatum & 2 & 0 & 0 & 0 & 0 & 0 & 1 & $2^{\star}$ \\
\hline
\end{tabular}

CSF, Cerebrospinal fluid; FNAC/Bx, fine needle aspiration cytology/ biopsy.

${ }^{\star}$ Histoplasmosis was diagnosed in one patient by histopathology of lymph node FNAC, as well as antibody detection from blood. 
Table 3. Opportunistic fungal infections and CD4 correlation

\begin{tabular}{|c|c|c|}
\hline Fungal infection (no. of patients, \%) & Mean CD4 count (cells $\mu \mathrm{l}^{-1}$ ) & Range (cells $\mu \mathrm{l}^{-1}$ ) \\
\hline Oral candidiasis $(22,36.7)$ & $222.5 \pm 133.7$ & $37-564$ \\
\hline PCP $(5,8.3)$ & $188.4 \pm 94.5$ & $94-326$ \\
\hline Cryptococcal meningitis $(5,8.3)$ & $138.8 \pm 92.11$ & $66-294$ \\
\hline Aspergillosis $(5,8.3)$ & $151.4 \pm 93.91$ & 29-268 \\
\hline Candida pneumonia $(3,5)$ & $161 \pm 73.08$ & $77-210$ \\
\hline Oesophageal candidiasis $(3,5)$ & $85 \pm 78$ & $37-175$ \\
\hline S. cerevisiae gastrointestinal infection ${ }^{\star}(1,1.6)$ & 100 & - \\
\hline Histoplasmosis $(2,3.3)$ & $315.0 \pm 35.35$ & $290-340$ \\
\hline Cryptococcal pneumonia $(2,3.3)$ & $144.5 \pm 31.31$ & 87-202 \\
\hline R. rubra oral ulcers $(1,1.6)$ & 52 & - \\
\hline Candiduria $(1,1.6)$ & 210 & - \\
\hline Candida diarrhoea $(1,1.6)$ & 256 & - \\
\hline
\end{tabular}

*This patient had oral thrush as well as severe diarrhoea due to S. cerevisiae.

could manifest (Abouya et al., 1992). Interestingly, the frequency of PCP has decreased in both developed and developing countries due to a combination of chemoprophylaxis with ART. The early AIDS-related mortality due to other causes may also reduce the rate of this disease (Chariyalertsak et al., 2001).

Four patients were diagnosed as having probable cases of invasive aspergillosis (positive antigenaemia), while one patient, with underlying neutropenia (CD4 count 29 cells $\mu \mathrm{l}^{-1}$ ), was diagnosed as a proven case of invasive pulmonary aspergillosis (positive direct microscopy, culture and antigen detection). Histoplasmosis was suspected in two

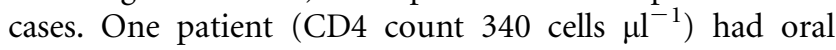
thrush with axillary lymphadenopathy, which showed a non-tubercular chronic granulomatous reaction on histopathology, while the other patient (CD4 count 290 cells $\mu \mathrm{l}^{-1}$ ) presented with hepatosplenomegaly with pancreatitis and HIV nephropathy. One case of Rhodotorula rubra oral ulcers, and one case with thrush and diarrhoea due to Saccharomyces cerevisiae were also diagnosed. No case of blastomycosis was seen (Tables 2 and 3).

Tuberculosis was the most common non-fungal aetiology seen in 18 patients $(30 \%)$, others included non-fungal diarrhoeas $(5 \%)$, cytomegalovirus oesophagitis $(5 \%)$, bacterial pneumonias (3.3\%), HIV encephalopathy $(3.3 \%)$, cerebral toxoplasmosis $(1.6 \%)$, aphthous ulcers $(1.6 \%)$ and HIV nephropathy (1.6\%).

In our study, only $14(23.3 \%)$ patients were on antiretroviral therapy (Fig. 2). The CD4 counts ranged from 29 to 564 cells $\mu \mathrm{l}^{-1}$. The median CD4 count was 157 cells $\mu \mathrm{l}^{-1}$ and the mean was $182.8 \pm 117.25$ cells $\mu \mathrm{l}^{-1}$. Thirty-six (60\%) patients had CD4 counts $<200$ cells $\mu \mathrm{l}^{-1}$, with CD4 counts $<100$ cells $\mu \mathrm{l}^{-1}$ in $33.3 \%$ and $<50$ cells $\mu \mathrm{l}^{-1}$ in $8.3 \%$ patients depicting a major population with severe immunosuppression. This finding is important as most fungal infections and tuberculosis seen in our patients are
AIDS-defining illnesses manifesting at significantly lower CD4 counts (CDC, 1985).

Various fungal infections were compared with the mean CD4 counts in these patients and they correlated well (Table 3). A total of $73 \%$ of our patients belonged to WHO stage 4 , while $23.33 \%$ were in stage 3 . Only two patients $(3.33 \%)$ belonged to stage 2 while none of our patients belonged to stage 1 (Fig. 3). Out of 14 patients in stage 3 , with no AIDS-defining illnesses, it was seen that 6 patients had a CD4 count of $<200$ cells $_{\mu l}{ }^{-1}$, and were in a danger of disease progression in the absence of ART prophylaxis had their CD4 counts not been measured. Thirty-one patients $(51.67 \%)$ were in Centers for Disease Control and Prevention (CDC) stage C3, followed by sixteen $(26.67 \%)$ in CDC stage C2. All 47 cases with 49 AIDS-defining illnesses or episodes belonged to stage C2 and C3 with CD4 count of $<500$ cells $\mu l^{-1}$, and none belonged to stage $\mathrm{C} 1$. However, five patients with

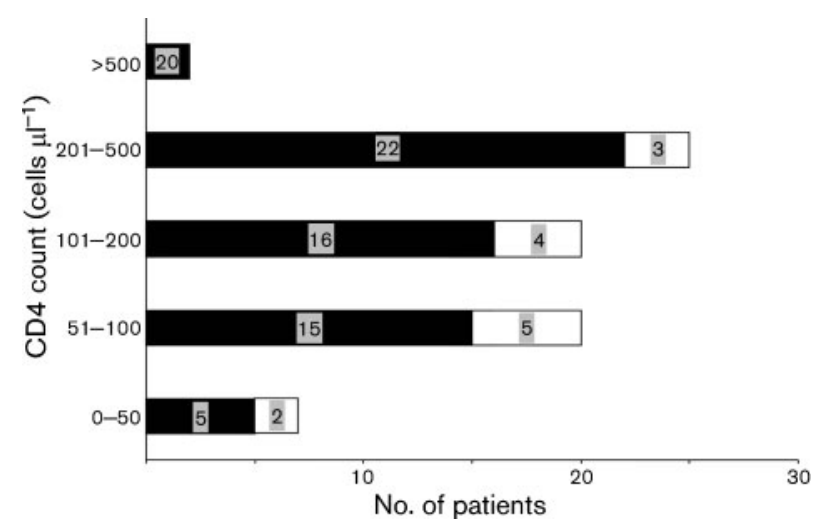

Fig. 2. CD4 profile and correlation of ART with CD4 profile. Black bars, total number of patients; white bars, number of patients on ART. 


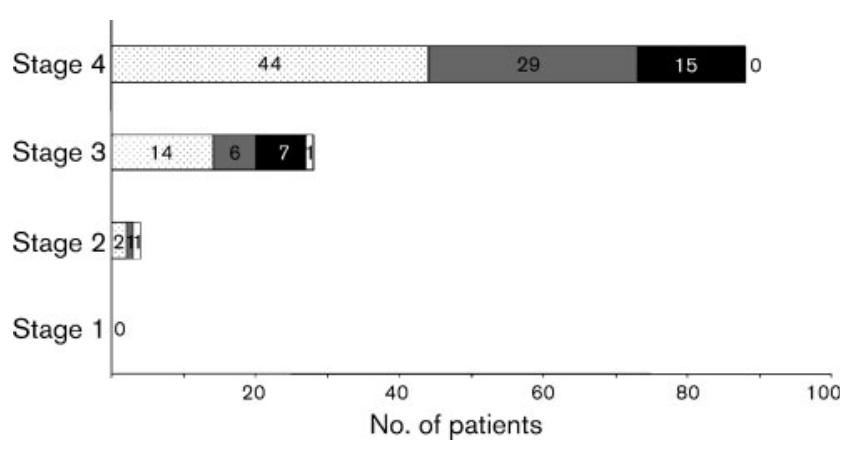

Fig. 3. WHO stages and correlation with CD4 counts. Spotted bars, total number of patients; grey bars, number of patients with CD4 count $<200$ cells $\mu l^{-1}$; black bars, number of patients with CD4 count 201-500 cells $\mu \mathrm{I}^{-1}$; white bars, number of patients with CD4 count $>500$ cells $\left.\mu\right|^{-1}$.

no AIDS-defining illnesses were grouped in B3 with CD4 count $<200$ cells $\mu^{-1}$, and had the advantage of getting ART and prophylaxis started in the absence of clinical conditions. The majority of AIDS-defining illness were tuberculosis $(36.7 \%)$, invasive candidiasis (18.4\%), cryptococcosis $(12.2 \%)$, PCP (10.2\%), cytomegalovirus oesophagitis $(6.1 \%)$, and histoplasmosis, HIV encephalopathy and recurrent bacterial pneumonias in $4 \%$ each, and cerebral toxoplasmosis in $2 \%$. None of the patients belonged to CDC stages A1, A2 or A3. This again proves the lack of awareness regarding the clinical spectrum and the various presentations of AIDS, in addition to the lack of diagnostic facilities at the peripheral health centres, due to which patients present very late to the tertiary health centres.

It was difficult to correlate statistically $\mathrm{WHO}$ and CDC staging because of our small sample size. However, we could assess to a limited extent the use of clinical diagnosis to predict the progression of HIV infection in a resource-poor setting, in a developing country like ours, as this study highlights the relationship between various clinical conditions and CD4 counts. However, it was realized that a longterm planned study might help in better interpretation and use of CD4 counts, and help in the provision of guidelines on possible points of intervention with prophylactic algorithms against various opportunistic infections in our setup.

\section{REFERENCES}

Abouya, Y. L., Beaumel, A. \& Lucas, S. (1992). Pneumocystis carinii pneumonia. An uncommon cause of death in African patients with acquired immunodeficiency syndrome. Am Rev Respir Dis 145, 617-620.

Aquinas, S. R., Tarey, S. D., Ravinderan, G. D., Nagamani, D. \& Ross, C. (1996). Cryptococcal meningitis in AIDS - need for early diagnosis. $J$ Assoc Physicians India 44, 178-180.

Bravo, I. M., Correnti, M., Escalona, L., Perrone, M., Brito, A., Tovar, V. \& Rivera, H. (2006). Prevalence of oral lesions in HIV patients related to CD4 cell count and viral load in a Venezuelan population. Med Oral Patol Oral Cir Bucal 11, E33-E39.
CDC (1985). Revision of the case definition of acquired immune deficiency syndrome for national reporting - United States. MMWR Morb Mortal Wkly Rep 34, 373-375.

Chariyalertsak, S., Sirisanthana, T., Saengwonloey, O. \& Nelson, K. E. (2001). Clinical presentation and risk behaviours of patients with acquired immunodeficiency syndrome in Thailand, 1994-1998: regional variation and temporal trends. Clin Infect Dis 32, 955-962.

Currie, B. P. \& Casadevall, A. (1994). Estimation of the prevalence of cryptococcal infection among patients infected with human immunodeficiency virus in New York City. Clin Infect Dis 19, 1029-1033.

de Repentigny, L., Lewandowski, D. \& Jolicoeur, P. (2004). Immunopathogenesis of oropharyngeal candidiasis in human immunodeficiency virus infection. Clin Microbiol Rev 17, 729-759.

Forbes, B. A., Sahm, D. F. \& Weissfeld, A. S. (2002). Laboratory methods in basic mycology. In Bailey and Scott's Diagnostic Microbiology, 11th edn, pp. 711-798. St Louis: Mosby.

George, J., Hamida, A., Das, A. K., Amarnath, S. K. \& Rao, R. S. (1996). Clinical and lab profiles of 60 patients with AIDS: a South Indian study. Southeast Asian J Trop Med Public Health 27, 686-690.

Kaur, A., Babu, P. G., Jacob, M., Narasimhan, C., Ganesh, A., Saraswathi, N. K., Mathai, D., Pulimood, B. M. \& John, T. J. (1992). Clinical and laboratory profile in AIDS in India. J Acquir Immune Defic Syndr 5, 883-889.

Koneman, E. W., Allen, S. D., Janda, W. M. \& Schreckenberger, P. C. (1997). Mycology. In Color Atlas and Textbook of Diagnostic Microbiology, 5th edn., pp 983-1057. Philadelphia, PA: Lippincott Williams \& Wilkins.

Kothari, K. \& Goyal, S. (2001). Clinical profile of AIDS. J Assoc Physicians India 49, 435-438.

Kumarasamy, N., Solomon, S., Paul, S. A. J., Venilla, R. \& Amalraj, R. E. (1995). Spectrum of opportunistic infections among AIDS patients in Tamil Nadu, India. Int J STD AIDS 6, 447-449.

Lattif, A. A., Banerjee, U., Prasad, R., Biswas, A., Wig, N., Sharma, N., Haque, A., Gupta, N., Baquer, N. Z. \& Mukhopadhyay, G. (2004). Susceptibility pattern and molecular type of species-specific Candida in oropharyngeal lesions of Indian human immunodeficiency viruspositive patients. J Clin Microbiol 42, 1260-1262.

Maenza, J. R., Keruly, J. C., Moore, R. D., Chaisson, R. E., Merz, W. G. \& Gallant, J. E. (1996). Risk factors for fluconazole-resistant candidiasis in human immuno-deficiency virus-infected patients. J Infect Dis 173, 219-225.

Martinez, M., López-Ribot, J. L., Kirkpatrick, W. R., Coco, B. J., Bachmann, S. P. \& Patterson, T. F. (2002). Replacement of Candida albicans with $C$. dubliniensis in human immunodeficiency virusinfected patients with oropharyngeal candidiasis treated with fluconazole. J Clin Microbiol 40, 3135-3139.

Milne, L. J. R. (1996). Fungi. In Mackie and McCartney Practical Medical Microbiology, 14th edn, pp 695-720. New York: Churchill Livingstone.

Mirdha, B. R., Banerjee, U., Sethi, S., Samantry, J. C. \& Malaviya, A. N. (1993). Spectrum of opportunistic fungal and parasitic infections in hospitalized AIDS patients. CARC Calling 6, 9-10.

Moore, G. S. \& Jaciow, D. M. (1979). Mycology for the Clinical Laboratory. Reston, VA: Prentice-Hall.

NACO (1999). Spectrum of opportunistic infections in AIDS in India. In Specialists Training and Reference Module, chapter 11, pp. 99-103 (http://www.nacoonline.org/publication/9.pdf). New Delhi: National AIDS Control Organisation.

Nissapatorn, V., Lee, C., Fatt, Q. K. \& Abdullah, K. A. (2003). AIDSrelated opportunistic infections in hospital Kuala Lumpur. Jpn J Infect Dis 56, 187-192. 
Phillips, P., Zemcov, J., Mahmood, W., Montaner, J. S., Craib, K. \& Clarke, A. M. (1996). Itraconazole cyclodextrin solution for fluconazole-refractory oropharyngeal candidiasis in AIDS: correlation of clinical response with in vitro susceptibility. AIDS 10, 1369-1376.

Rosen, M. J. (1994). Pneumonia in patients with HIV infection. Med Clin North Am 78, 1067-1078.

Sivaraman, V., Gilbert, F. \& Rao, R. S. (1992). HIV infection and pulmonary tuberculosis: report of 6 cases. Indian J Tuberc 39, 35-39.
Udwadia, Z. F., Doshi, A. V. \& Bhaduri, A. S. (2005). Pneumocystis carinii pneumonia in HIV infected patients from Mumbai. $J$ Assoc Physicians India 53, 437-440.

UNAIDS/WHO (2005). AIDS Epidemic Update: December 2005. Geneva: UNAIDS and WHO.

Vajpayee, M., Kanswal, S., Seth, P. \& Wig, N. (2003). Spectrum of opportunistic infections and profile of CD4 + counts among AIDS patients in north India. Infection 31, 336-340.

White, D. A. \& Zaman, K. M. (1992). Medical management of AIDS patients. Med Clin North Am 76, 19-44. 